\title{
A Study on Hong Kong Nanyang-themed Films During the Cold War
}

\author{
Xiaoyun $\mathrm{Li}^{1{ }^{1, *}}$ \\ ${ }^{1}$ Beijing Film Academy, Beijing 100088, China \\ *Corresponding author. Email: lixiaoyunxmu@163.com
}

\begin{abstract}
In terms of geographical locations, Hong Kong acts as an intermediate terminal for migrants who move from the mainland to Nanyang. In addition, due to the joint influence by British Colonies, Hong Kong has always been closely associated with Nanyang. In 1950s, there were a lot of Hong Kong films directing at Nanyang Chinese migrants. On the one hand, Hong Kong films always depend heavily on overseas Chinese market. The films about the life of Nanyang Chinese migrants reflect the real life of Nanyang migrants, thus having a broad audience foundation at home and abroad; on the other hand, in terms of narrative contents, the Nanyang narrations are actually closely associated with the international situation and social reality of Hong Kong, which implicitly and explicitly reflects Hong Kong's new city and identity imagination after the war. In this way, not only does it realize Hong Kong's self-subjectivity, but also it is the initiation of Hong Kong consciousness.
\end{abstract}

Keywords: Hong Kong films, Nanyang-themed films, Chinese migrants, 1950s.

\section{INTRODUCTION}

The so-called "Nanyang" refers to the Southeast Asia region today, including Thailand, Myanmar, Vietnam, Laos, Brunei, East Timor, Cambodia, the Philippines, Singapore, Malaysia, and Indonesia. Due to the advantageous geographical location and the influence of political and economic factors, Southeast Asia has always been the main destination for people from the southeast coast of China to emigrate overseas. Since the 15 th century, Chinese people have engaged in maritime trade in Southeast Asia. The waves of "Sailing South" immigration have occurred from time to time since the Qing Dynasty.

From a geographical perspective, Hong Kong has acted as a midway stop for mainland migrants to Southeast Asia, as a large number of north-south migrants would pass here. In view of the coinfluence from being the British colonies, and during the Occupation Period, a large number of Hong Kong residents fled to Southeast Asia, Hong Kong and Southeast Asia had a rather close relationship. The scholar Hamishita Takeshi even described the close ties between Hong Kong and Singapore as a "conjugal relationship, brotherhood" [1]. During the Cold War, due to the physical and psychological barriers and obvious separation between Hong Kong and the mainland China, Hong Kong was more closely connected with the Southeast Asian Chinese.

During this period, Hong Kong film companies, both on the left and on the right, made a number of films on the theme of Chinese migrants in Southeast Asia. The most famous one is the "Nanyang Trilogy", including "Blood Stains the Valley of Love", "She Married an Overseas Chinese", and "The Whispering Palm" (1957), made by KONART. Other representatives include "Malaya Love Affair" (1954) by Grandview, "A Teacher's Reward" (1955) by Sun Luen, "Wind and Rain in Chinatown" (1956), "Romance in Singapore" (1956), and "The Old Man from Southeast Asia" (1958) by Motion Picture General Investment, and "The Merdeka Bridge", "The Tax Files", and "Paper Marriage" (1959) by Shaw Brothers and so on.

\section{FOREIGN LANDSCAPE: FRAMING ON THE SPOT AND THE BROAD MASS BASE}

In view of Hong Kong's immigration history, Hong Kong has always been a major transit stop 
and a free port for Chinese people to immigrate to Southeast Asian countries. Especially in the late 18th century, when Western colonists began to incorporate Southeast Asia into their colonial system, the large-scale trades in Southeast Asia required a large amount of labor. Accordingly, Western colonists launched a number of preferential policies to recruit massive "contracted Chinese workers" from the southeast coast of China for hard labor, historically known as "selling piglets" (a derogatory term of Chinese workers) and "being a coolie", which drove Chinese migrants to move to Southeast Asia. For the part of China, the economic decline and social chaos caused by years of war forced people to emigrate overseas. With the increasing number of migrants, up to the 19th century, "a Chinese society that maintains close ties with the ancestral place was formed overseas" [2]. Therefore, Southeast Asia has a vast base of overseas Chinese, who established a wide community network in Southeast Asia and formed a vast overseas market for Hong Kong movies.

Although "Nanyang" can be used to refer to the entire Southeast Asian region, the stories of Hong Kong films with the theme of "Nanyang" made during that period mainly occurred in Singapore and Malaya. At that time, Singapore was still a colony directly under the British; "Malaya" refers to "British Malaya", which had a turbulent political scene in the late 1950s, but the "Malaya" appeared in films is mainly within the contemporary peninsula of Malaysia. "Tangshan" corresponding to "Nanyang" in Nanyang-themed films refers to "The Land Ruined in the Great Tang Dynasty" originally. For the reason, China in the Tang Dynasty enjoyed a great reputation and had a widespread influence overseas, so that everything related to China was still called "Tang" in other countries from then on, as Overseas Chinese call themselves "Tang people", call Chinese characters "Tang characters", call their mother tongue "Tang language", and call their homeland in China "Tangshan".

As for the advertisements of these films made that time, since these Nanyang-themed films were shot in Singapore and Malaya with mountains of difficulties in funding and manpower overcome, the advertisements were also "shot on site". During the process of making, Nanyang-themed films received widespread support from the Chinese in Southeast Asia and were also favored by audiences in Southeast Asia and Chinese audiences in other regions after being released. According to director Chu Yuan, "Newly made clear image can increase the popularity among the audience, and moreover, can increase appeal in promotion" [3], and Gin Yip Hoh, the head of KONART, also said, "In fact, our script (referring to the "Nanyang Trilogy") is also created according to the scene" their best to show the real sceneries of Singapore and Malaya that time, such as natural scenery represented by the tin mines, sunny beaches, and palm trees in Ipoh, Malaya, as well as landmark attractions such as the railway station, the Clifford Pier, Anderson Bridge, Chinatown (Kreta Ayer), especially the clip of the couple traveling in "The Whispering Palm" and "Romance in Singapore". The scenes are just like tourism promotional videos of Singapore and Malaya. It not only made the films intimate for the Chinese in Southeast Asia, but also presented unfamiliar and exotic geographical landscape to the Hong Kong audience.

Law-Lin Tsz, a Cantonese film maker, is a representative of making Nanyang-themed films in Singapore and Malaya in the 1950s. She is the first Hong Kong movie star to perform in Southeast Asia after the World War II. In the "Malaya Love Affair", a film wrote, directed and performed by Law-Lin Tsz in 1954, a Chinese lady who loves education went to Nanyang to find her father, and then founded an overseas Chinese volunteer school there under the influence of a Chinese compatriot who dedicated his life to Chinese education. As Law-Lin Tsz said in an interview during the film promotion period: "I arrived at Malaya three years ago to perform for the film in various places, and I can never forget the diligence and simplicity of the overseas Chinese here. Once upon a time, a few young people engaged in local education came to interview me, which again aroused my willingness and interest to make a film focusing on the Chinese in Malaya, revealing their dedication throughout the film." [5] From a female perspective, Law-Lin Tsz intertwined love, ethics, sibship of overseas Chinese and love for education in detail. Following the film, "Chinese Education" and "Seeking for Overseas Relatives/Lover" became the two main themes of movies about Chinese migrants in Southeast Asia during that period.

\section{3. "CHINESE EDUCATION": REALISTIC CONCERN OF CHINESE MIGRANTS IN SOUTHEAST ASIA}

For overseas Chinese, the same ties of blood, clan, and culture in the foreign land are more necessary to relieve the feeling of homeless and to 
maintain their emotional connection with the motherland. Language is the basis for creating an "Imaginary Community", and for overseas Chinese, language education is of great significance for its key role in survival and cultural inheritance. According to Professor Philip A. Kuhn, "Language and education have always been emotional issues. In the eyes of Chinese people, either the identity of the Chinese individual or the Chinese society as a whole depends on the inheritance of the Chinese language. Chinese-based Education is the one and only way for the inheritance of the Chinese language. The idea that the common language is the benchmark for modern Chinese identity was sourced from the educational philosophy introduced to Malaya after the May Fourth Movement in 1919, which puts modern national consciousness on cultural benchmarks." [6] It reveals that Chinese language education plays an important role in the cultural identification of Chinese and has always been valued by overseas Chinese. In addition, as far as the specific situation in Malaya during this period is concerned, the 1950s witnessed the rise of the anti-colonial wave in Singapore and Malaysia. "The Chinese language of the Southeast Asian Chinese, either in Chinese education or dialect use, was under the dual oppression and impact of the English advantage in the process of modernization and the local language advantage of the nationalist movement" [7], so the Chinese language education of local Chinese in Malaya during that period became a practical issue of great concern to the Chinese society that time.

In addition to Law-Lin Tsz's "Malaya Love Affair", "A Teacher's Reward" produced by Sun Luen and "The Whispering Palm" in the "Nanyang Trilogy" produced by KONART also chose the theme of local Chinese language education conducted by the Chinese in Southeast Asia. However, the cautiousness and obscurity in handling such subjects are also revealed in these films. As for "A Teacher's Reward", the prominent conflict in the film between Jiang Xiuqiao, an old pedant representing feudal patriarchy, and Lin Zhihua, a young man representing progressive thinking, implies the ideological contradiction between the right wing and the left wing. However, as the representative of the left wing, Lin Zhihua, instead of taking a tough stance, submitted to humiliation and was even criticized by his lover, who embraced a proactive attitude in fighting, for being "weak". Unfortunately, Lin Zhihua's lover had to returned to China for being "the weaker gender", and Lin persisted to stay in Nanyang for thirty years while enduring humiliation with his affection sacrificed. As for "The Whispering Palm", the prominent conflict in the film between Yue Ming and his father-in-law/wife on the career of education or business was simplified into a conflict caused by the difference in ambition. The film cast a veil over the reason for the difference in ambition, namely, the ideological contradiction between the left wing and the right wing. The political contradiction was hidden behind the family contradictions, without referring to the social reality of racial politics and the equivalence of development of Chinese education to "Communism", which seriously hindered the development of Chinese education in Singapore and Malaya. In fact, dealing with politically sensitive issues obscurely was exactly a commercial strategy adopted by Hong Kong films during the Cold War. In particular, the British colonial government carried out a more stringent film censorship system in Southeast Asia in the 1950s. In order to avoid the impact of political issues in the Southeast Asia, these Hong Kong films exercised great care against such subjects.

\section{4. "SEEKING FOR OVERSEAS RELATIVES/LOVE": POSTWAR URBAN IMAGINATION IN HONG KONG}

The subject of "Seeking for Overseas Relatives/Love" prevailed in Hong Kong's Nanyang-themed films during that period. Such films generally adopted the framework of family ethics, highlighting love stories and family, with family affection/love, the most empathetic emotional element, running through the whole film. The benefits of this strategy include strengthening the emotional connection between overseas Chinese and their homeland, imaginative solution to the difficulties and obstacles encountered overseas, and conveying the preaching messages. As said by Gin Yip Hoh, the head of KONART, "Reason with a beating about the bush approach" [8].

First of all, regarding the subject of "Seeking for Overseas Relatives", the characters from China in these films always have relatives in Southeast Asia, and this alone can arouse sympathy from the vast number of the Chinese in Southeast Asia. For both the Chinese labor "traded" to Southeast Asia in the early years and the Chinese who moved to Southeast Asia due to reasons such as World War II and the Civil War in China, as overseas Chinese separated from their relatives, their emotional 
resonance is mostly subject to the contact with their hometown and relatives. Among these films, "forgotten wife" is the most common subject. For example, "She Married an Overseas Chinese" and "Wind and Rain in Chinatown" are all about the story of a forgotten wife who went to Southeast Asia to seek for her "heartless and ungrateful husband", conveying messages of family and moral values.

Secondly, the subject of "Seeking for Overseas Lover" is more modern. The pursuit of love reflects yearning for freedom, democracy, and personal dreams. The main target of this subject is the urban middle class, such as "Romance in Singapore", "Blood Stains the Valley of Love", and "The Merdeka Bridge", etc., which are all about the love story between Tangshan and Nanyang. The modern urban scenes and middle-class characters in these films actually represent the post-war urban landscapes familiar to Hong Kong people, and these stories also contain a moralistic meaning. For example, in the "Blood Stains the Valley of Love", which combines romantic love with film noir techniques, the male protagonist Ye Jing expressed the theme in the end, "It turns out that there is really no black magic in the world, but only the human nature that is devoid of conscience and morality resulted from struggle for property, and love!" The impetuous moods including greed, corruption, and indulgence in the modern society displayed in these films all reflect the criticism against the "derivative of Hong Kong city life (and certainly the derivative of the life of Nanyang migrants)". [9] What's more, for example, the end of "Blood Stains the Valley of Love" with the back figure of the Chinese Ye Jing and the Malayan Ah $\mathrm{Li}$ moving ahead shoulder to shoulder reflects an imaginative dissolution of the long-standing racial conflicts and prejudices in Malaya, which is equally influential for Hong Kong and Macao audiences in a society with a mixture of Chinese and foreigners. In the meanwhile, the location of the place "Tangshan" in these Nanyang-themed movies was not clearly specified. For example, in the "Nanyang Trilogy" of KONART, the location shown in the opening captions of "She Married an Overseas Chinese" is "Macao", and although the other two films have no caption indicating their locations, it can be known from the dialogue between the characters and the landscape of Victoria Harbour that "Tangshan" herein refers to "Hong Kong". It suggests that, on the one hand, making Macau and Hong Kong the representative of the motherland "Tangshan" concealed the colonial identity, showing their emotional connection with Chinese culture, while arousing the affection of the Chinese audience in Nanyang for the motherland; On the one hand, for migrants who moved from the mainland to Hong Kong, the mainland is the real "Tangshan", so local Hong Kong and Macao audiences naturally felt the same.

\section{CONCLUSION}

It can be said that during that period, Hong Kong films built a cultural bridge for both Hong Kong people and the Chinese in Southeast Asia to the motherland, revealing the cultural situation of the separated Chinese. In the meanwhile, the films reflected the status of the post-war Hong Kong society with the society of Nanyang, which shared the same colonial experience with Hong Kong and had a large number of overseas Chinese, serving as a mirror.

More importantly, the Chinese in Hong Kong and Nanyang, during that period, were experiencing a transitional period in terms of society, culture and sense of belonging. In other words, they faced "dual problems of local and homeland, assimilation and alienation" [10] -As far as Hong Kong is concerned, from the Cold War period, the ties between the mainland China and Hong Kong had been greatly weakened. In view of the actual border barriers, the development gap between the mainland and Hong Kong kept increasing, and the local consciousness of Hong Kong people gradually emerged; As far as Nanyang is concerned, at the Bandung Conference in 1955, the Chinese government announced the abandonment of the dual nationality policy and encouraged overseas Chinese to join the country of residence, proclaiming the "end of the Overseas Chinese Era" [11], the dual connection between the Chinese in Southeast Asia and China in blood tie and politics gradually transformed into a consanguinity-based emotional connection. The Chinese in Southeast Asia adapted to the local society more with a higher sense of identity, and actively participated in the independence of Singapore and Malaysia. This is the evolution period of the identity mobility of the Southeast Asian Chinese from "fallen leaves back to the roots" to "put down roots" in that period as analyzed by Professor Wang Gungwu. [12]

As a reflection in the Nanyang-themed films made during that period, the Chinese in Nanyang gained more local consciousness, reflecting the local consciousness of Hong Kong residents. For example, "Malaya Love Affair", "The Old Man 
from Southeast Asia", and "She Married an Overseas Chinese" all did their best to highlight the fighting spirit of the overseas Chinese working in the local area. In "She Married an Overseas Chinese", the heroine failed to find her husband at first and was not ready to return to Tangshan. Instead, she planned to stay in the local area and work on her own, and finally reunited with her husband to work together in a tin mine in Ipoh. This sense of local identity was also conducive to promoting the recognition of Hong Kong by local audiences in Hong Kong that time. After the war, Hong Kong seized the opportunity to transform from entrepot trade to labor-intensive industry, with the process of industrialization accelerated, needing a large amount of labor. However, the British Hong Kong government did not released corresponding supporting policies to support the industry and provide livelihood security for either migrants from the north or local residents. At that time, this kind of spiritual support was necessary for them to work hard. The success in Hong Kong won by their own efforts gave them a higher sense of belonging to the city, which promoted the Hong Kong audience's local consciousness and the initiation of Hong Kong identity.

\section{AUTHORS' CONTRIBUTIONS}

This paper is independently completed by Xiaoyun Li.

\section{REFERENCES}

[1] Takeshi Hamashita, Large View of Hong Kong - Asia Network Center, Taipei: Hometown Publishing Co., Ltd./Newton Publishing Co., Ltd., 1997, p20.

[2] Philip A. Kuhn, Chinese among Others: Emigration in Modern Times, Lanham: Rowman \& Littlefield Publishers, 2008, p255.

[3] Chu Yuan, Roca, "Interview with Chu Yuan", Edited by Hong Kong Urban Council, The Image of Overseas Chinese in Films, Hong Kong: Hong Kong Urban Council, 1992, p50.

[4] Gin Yip Hoh, "Oral History: Gin Yip Hoh", Edited by Huang Ailing, Great Modern. Urban Style of KONART, Hong Kong : Hong Kong Film Archive, 2006, p155.

[5] Anonymous, Hong Kong Commercial Daily (Hong Kong), Quoted from: "Malaya Love Affair"

Database

[EB/01]. http://gy99.org/database/dianying/405727.htm 1, 1954- 9-5/2021-8-30.

[6] Philip A. Kuhn, Chinese among Others: Emigration in Modern Times, Lanham: Rowman \& Littlefield Publishers, 2008 , p315.

[7] Zhou Ning, History of Chinese Drama in Southeast Asia (Volume 1), Xiamen: Xiamen University Press, 2007, p21.

[8] Gin Yip Hoh, "Oral History: Gin Yip Hoh", Edited by Huang Ailing, Great Modern. Urban Style of KONART, Hong Kong: Hong Kong Film Archive, 2006, p164.

[9] Stephen Teo. Singapore Screen Memory: "Nanyang Trilogy" of KONART, Edited by Huang Ailing, Great Modern- Urban Style of KONART, Hong Kong: Hong Kong Film Archive, 2006, p130.

[10] Zhou Ning, History of Chinese Drama in Southeast Asia (Volume 1), Xiamen: Xiamen University Press, 2007, p5.

[11] Liu Hong, The Evolution of Chinese Society in Singapore After the War: the Motherland Feelings, Regional Network, Global Vision, Xiamen: Xiamen University Press, 2003, p9.

[12] Wang Gungwu. Chinese Overseas and China: Selected Works of Wang Gungwu, Shanghai: Shanghai People's Publishing House, 2013, pp.294-313. 